\title{
Cotinine in an Ultrafiltrate of Saliva
}

\author{
Willfried Schramm, Ph.D., ${ }^{*},{ }^{\prime}$, Ovide F. Pomerleau, Ph.D. $\ddagger$ \\ Cynthia S. Pomerleau $\ddagger$ and Harry E. Grates $\dagger$ \\ ${ }^{*}$ Reproductive Sciences Program and Bioengineering Program, University of Michigan, 300 North \\ Ingalls, Ann Arbor, Michigan 48109; †BioQuant, Inc., 1919 Green Road, Ann Arbor, Michigan \\ 48105; and $¥$ Department of Psychiatry, Behavioral Medicine Laboratory, University of Michigan, \\ Riverside Building, 900 Wall Street, Ann Arbor, Michigan 48105
}

Background. We have developed a device for the simplified collection of a prepurified sample of saliva in the mouth.

Method. The device is based on the principle of an osmotic pump and accumulates about $1.2 \mathrm{ml}$ of an ultrafiltrate of saliva within $8 \mathrm{~min}$. We have investigated the ultrafiltrate for its utility as a biological medium in the evaluation of cigarette smoking status.

Results. (a) In 58 matched samples from 13 subjects, the correlation coefficient for the cotinine concentration in the saliva and the ultrafiltrate was 0.95 ; (b) in matched plasma and ultrafiltrate samples from 27 smokers, the correlation coefficient for the cotinine concentrations was 0.96 with plasma containing 1.2 times the ultrafiltrate mean; (c) in a nonsmoker, elevated cotinine levels could be detected in the ultrafiltrate more than $24 \mathrm{hr}$ after smoking 2 cigarettes, and the pattern of rise and decrease reflected that in whole saliva; and (d) in a habitual smoker, the mean cotinine concentration in the ultrafiltrate was $157 \mathrm{ng} / \mathrm{ml}$ (SD \pm $25.7 \mathrm{ng} / \mathrm{ml}$ ) during a period of smoking 15 cigarettes per day and dropped to a mean of 47 $\mathrm{ng} / \mathrm{ml}(\mathrm{SD} \pm 10.5)$ when smoking was reduced to 5 cigarettes per day; after cessation of smoking, detectable concentrations of cotinine persisted for up to 5 days.

Conclusion. The device facilitated the aesthetic, noninvasive collection of a biological sample useful in the validation of smoking status. (c) 1992 Academic Press, Inc.

\section{INTRODUCTION}

Traditionally, determinations of physiologically active substances have been made using blood as the biological medium. The collection of body fluids by invasive methods has its limitations for obtaining data that require measurements from large populations in diverse settings (e.g., in epidemiological studies and in longitudinal studies involving infants, children, adolescents, adults, smokers, and nonsmokers). Obtaining biological fluids by simple, acceptable, noninvasive methods will simplify such investigations. Urine sampling, although noninvasive, cannot be considered as an ideal solution for large-scale studies. From this perspective, it is not surprising that until 1987, little information was available on smoke intake in adolescents based on biochemical measures (1-3). Many of the pioneering studies on passive exposure to tobacco smoke before the mid-1980s were carried out in small numbers of subjects and in somewhat atypical samples such as hospital outpatients (4) or men attending health screening examinations (5).

Recently, substantial progress has been made in studies using saliva as a medium from comparatively large numbers of individuals for the investigation of

\footnotetext{
1 To whom reprint requests should be addressed.
} 
tobacco smoking $(6,7)$. Quantitative evaluation of passive exposure to tobacco smoke has also become more accurate (8); see also (9). Without noninvasive sample collection from a comparatively large number of subjects, these studies would have been almost impossible.

The half-lives of cotinine in plasma, urine, and saliva are similar (10-12), so that, in principle, any of these liquids can be used for diagnostic determinations. Mean concentrations in plasma and saliva are very similar to one another, with concentrations in urine being about twice as high (13). Since the excretion rate in urine can vary substantially with the volume of liquid uptake, however, values obtained from urine are usually much less reliable, unless an additional determination of creatinine is made to correct for excretion rates.

In comparison, salivary flow rate does not affect significantly the concentration of cotinine $(14,15)$. Although a good intercorrelation among cotinine concentrations in three body fluids-plasma, urine, and saliva-has been reported $(4,16)$, there is still some unexplained variability between plasma and saliva values (17, 18). The problems include elevated cotinine readings following heavy exposure and erratic values for nicotine (17). Possibly some of this unexplained variability is related to certain technical limitations in the use of expectorated saliva as a medium. Collection and processing present many difficulties. Food intake can affect the consistency and appearance of saliva for up to several hours and can contribute gross contaminants; saliva also can be contaminated with traces of blood. Saliva always contains nonfood particulate matter (oral squames), mucopolysaccharides, and mucoproteins that contribute to its highly viscous, "stringy," "sticky" consistency. Some drugs are known to bind to cellular debris and make an accurate estimation in saliva difficult (19).

The viscosity of saliva makes it extremely difficult to handle in the laboratory. The general, albeit time-consuming, method of centrifugation to separate undissolved matter from the solute has met with only limited success. Pipetting and aliquoting are laborious as well as extremely inaccurate. Therefore, technicians often show an aversion to handling saliva samples. Further, some people resist expectorating. The collection procedure is not straightforward and is difficult to accomplish in an inconspicuous and aesthetically pleasing way. Consequently, the request for samples of saliva sometimes leads to a psychological block that results in a "dry mouth."

We have developed a saliva collection device that overcomes many of the above-mentioned technical and aesthetic problems (20-22). It consists of a semipermeable membrane that encloses an osmotically active substance. When the device is kept in the mouth, salivary flow is moderately stimulated. A clear, protein-free aqueous ultrafiltrate of saliva is obtained in situ during the process of collection. The protein-bound fraction of drugs and other substances from potential blood contamination is excluded, and potential degradative processes, such as further enzymatic metabolism, are almost totally eliminated. Unlike whole saliva, the ultrafiltrate does not require centrifugation, since no precipitate is present.

The device can be used for the collection of saliva by untrained individuals in an aesthetic way for subsequent nicotine/cotinine measurements. It facilitates collection in studies involving large numbers of subjects; collection in nonmedical 
facilities; collection in schools, workplaces, and at home; and collection of saliva from clients of insurance companies. In this communication, we report on the validation of the ultrafiltrate, collected in the mouth, for the measurement of nicotine and cotinine.

\section{MATERIALS AND METHODS}

\section{Collection Device}

The device consisted of a semipermeable cellulose membrane ( $20 \mu \mathrm{m}$ thickness; molecular cutoff: 12,000 Da; Cuprophan; Enka AG, Germany) composed of two discs (35 mm diameter) bonded with polyurethane (Tycel; Lord Corporation, Erie, PA) at the periphery, the adhesive forming a ring of $5 \mathrm{~mm}$ width. Granular sucrose $(0.75 \mathrm{~g})$ was deposited inside the membrane. After collection of the ultrafiltrate of saliva, the liquid was extracted prior to assaying by puncturing the membrane with a hypodermic needle and transferred with disposable pipettes.

\section{Sample Collection}

Samples were collected from 13 volunteers (seven males and six females) between 20- and 46-years-old who were habitual smokers and reported smoking between 5 and 30 cigarettes per day (self-reported; mean: 18.8; SD \pm 7 ). Unless otherwise indicated, at least $60 \mathrm{~min}$ was allowed to elapse after smoking of the last cigarette before sample collection. Saliva was obtained by spitting into a $12-\mathrm{ml}$ polypropylene jar. Subjects were advised to accumulate saliva for about $5 \mathrm{~min}$ in the mouth before expelling saliva into the container. This reduces frequent expelling of froth that contains little liquid. After the collection of whole saliva, the subjects collected ultrafiltrate with the device. The device was immersed in tap water for a few seconds and then placed into the mouth. Subjects were notified to rotate the device frequently in the mouth. The device was expelled by dropping into a polycarbonate container $(30 \mathrm{ml})$ after a minimum of $8 \mathrm{~min}$. The collected volume of ultrafiltrate was $1.2 \pm 0.1 \mathrm{ml}$ (mean $\pm \mathrm{SD}$ ). Subjects were instructed not to touch the device or any parts of the inside of the containers to avoid contamination with residues of nicotine.

In a second study, 27 male smokers ranging in age from 23 to 44 (mean \pm SD $=32.9+6.0$ years) and smoking $15-30$ cigarettes per day (mean $\pm \mathrm{SD}=22.6 \pm$ 4.7) were recruited from the local community to participate in a laboratory study of predictors of ability to abstain from smoking. Blood samples were withdrawn from subjects 1 week after they were challenged to abstain from smoking, with a monetary bonus paid to those who succeeded in reaching cotinine values of 0 $\mathrm{ng} / \mathrm{ml}$. At that time, a sample of ultrafiltrate of saliva was obtained as well for purposes of the present study. This procedure enabled us to obtain data for cotinine levels over a wide range of values, since the sample included subjects who were entirely successful in abstaining, subjects who were partially successful, and subjects who did not change their smoking behavior. Nicotine levels were also analyzed.

In a third study, a nonsmoking, 46-year-old, healthy male volunteer was recruited. The subject smoked two cigarettes (Marlboro Lights; tar: $11 \mathrm{mg}$; nicotine: 
$0.8 \mathrm{mg}$; carbon monoxide: $12 \mathrm{mg}$ per cigarette) by inhaling the smoke. Samples (saliva and ultrafiltrate) were collected as described above prior to smoking and thereafter in different intervals up to $28 \mathrm{hr}$ after smoking. All samples were collected at home, stored in the home freezer, and brought to the laboratory after the collection was completed.

In a fourth study, a habitually smoking, 21-year-old, healthy female volunteer was recruited. After smoking an average of 15 cigarettes per day (13 to 16), the subject remained abstinent for 14 days and then resumed smoking (4 to 7 cigarettes per day). Samples were collected as described above before, during and after stopping smoking. Samples were also collected at home, stored in the freezer, and brought to the laboratory after the collection was completed.

\section{Sample Preparation}

All samples were stored at $-20^{\circ} \mathrm{C}$ prior to analysis. Whole saliva was centrifuged before extraction to remove particulate matter. The semipermeable membrane of the devices was punctured with a pasteur glass pipette and the ultrafiltrate was measured for density, $C_{\mathrm{w}}$. To this end, $1 \mathrm{ml}$ of liquid was weighed on an analytical balance at $22^{\circ} \mathrm{C}$. Blood samples were collected in EDTA tubes, the precipitate was separated by centrifugation at $4^{\circ} \mathrm{C}$, and the plasma was stored frozen until analyzed.

\section{Sample Analysis}

Saliva and ultrafiltrate was assayed for nicotine and cotinine by HPLC according to a method described for plasma (23). Briefly, 2-phenylimidazole was added as internal standard to the samples prepared as described above, the liquids were extracted with methylene chloride after deproteinization with trichloroacetic acid, and the organic solvent was evaporated and the residue reconstituted in $30 \mu$ of mobile phase for HPLC separation. The limits of detection for nicotine and cotinine are 1 and $3 \mu \mathrm{g} / 1$, respectively. The quantitative analysis was performed in Dr. M. Hariharan's laboratory.

The ultrafiltrate contains sucrose that displaces a certain volume of pipetted ultrafiltrate. To account for the concentration of analytes in the aqueous component, we calculated a correction factor, $f$, derived from the density, $C_{\mathrm{w}}$, of the solution. The correction factor as a function of the density follows a polynomial regression according to the equation (22):

$$
f=426.8-1495.8 C_{\mathrm{w}}+1965 C_{\mathrm{w}}{ }^{2}-1146 C_{\mathrm{w}}{ }^{3}+250.8 C_{\mathrm{w}}{ }^{4} .
$$

The concentration for the aqueous medium of the ultrafiltrate is obtained by multiplying the concentration determined for the ultrafiltrate by the factor $f$ (i.e., actual concentration $=f \times$ measured concentration).

\section{RESULTS}

Collection using the device was considered by $75 \%$ of the first users to be more convenient and aesthetic than spitting. When subjects used the device more than one time, all preferred this method of sample collection. 


\section{Correlation of Cotinine Concentrations in Saliva vs Ultrafiltrate}

Cotinine concentrations in saliva and ultrafiltrate were highly correlated $(r=$ 0.95 ; Fig. 1, left). The liquid in the osmotic device contained about $74 \%$ of the cotinine in saliva. The concentration of nicotine in saliva and the ultrafiltrate correlated moderately $(r=0.76)$ and the linear regression followed the equation $y=8.8 \times 0.8 x$. Between 71 and $80 \%$ of the concentration in saliva was found in the ultrafiltrate. Nicotine values were out of the expected range (the majority $>50$ $\mathrm{ng} / \mathrm{ml}$ ), suggesting that nicotine from contact with cigarette remains sequestered in the mouth for more than $1 \mathrm{hr}$.

\section{Correlation of Cotinine Concentrations in Plasma vs Saliva Ultrafiltrate}

Mean plasma cotinine \pm SD for the 27 subjects in the second study was $162.4 \pm$ $117.3 \mathrm{ng} / \mathrm{ml}$ (Fig. 1, right). Using a constant correction factor of 1.25 , the corresponding saliva ultrafiltrate value was $135.4 \pm 99.1$. Thus, plasma mean was 1.2 times the ultrafiltrate mean. The Pearson correlation coefficient of plasma with ultrafiltrate values for the 27 subjects was 0.96 .

The mean density $( \pm \mathrm{SD})$ for the 12 subjects for whom density data were available was $1.21 \pm 0.9$. The mean plasma level for these 12 subjects was $135.5 \pm$ $128.0 \mathrm{ng} / \mathrm{ml}$ and the corrected mean ultrafiltrate level was $108.1 \pm 104.5 \mathrm{ng} / \mathrm{ml}$, resulting in a plasma mean that was 1.25 that of the ultrafiltrate mean. Correlation of plasma values with corrected ultrafiltrate values yielded a correlation coefficient of 0.99 .

The study did not produce meaningful nicotine data. For several subjects, nicotine values exceeded $200 \mathrm{ng} / \mathrm{ml}$, and for two the values exceeded $800 \mathrm{ng} / \mathrm{ml}$; no subject, even those with 0-nicotine levels using plasma data, achieved ultrafiltrate levels of $0 \mathrm{ng} / \mathrm{ml}$.
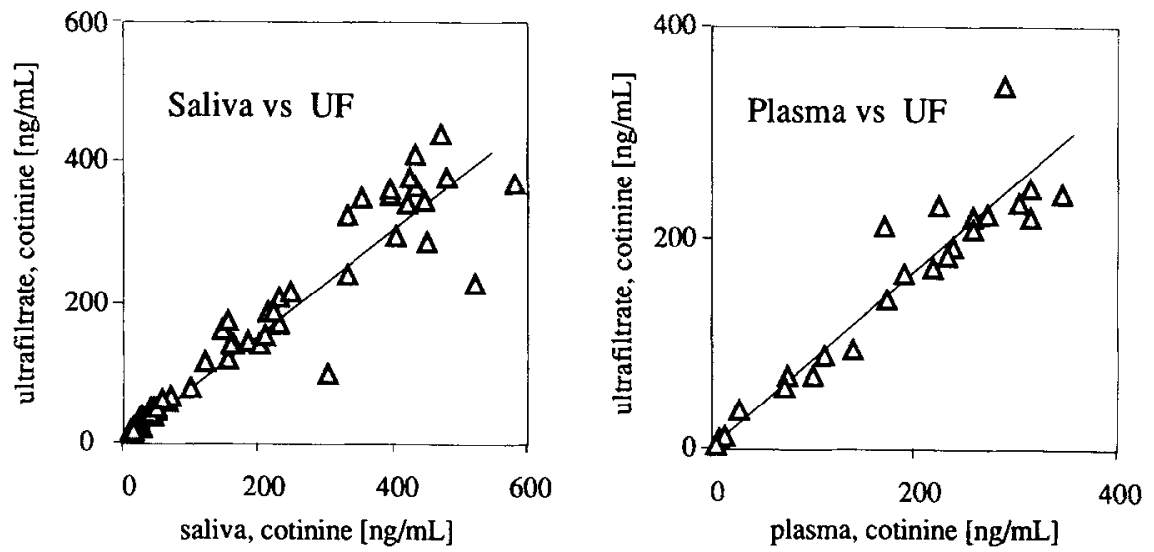

FIG. 1. (Left) Correlation of cotinine concentrations in saliva and the ultrafiltrate of saliva in $\mathbf{5 8}$ matched samples. The equation for linear regression is $y=11.57+0.74 x$; the correlation coefficient is $r=0.95$. (Right) Correlation of cotinine concentrations between plasma and the ultrafiltrate of saliva in 27 matched samples. The equation for linear regression is $y=5.39+0.80 x ; r=0.96$. 
Cotinine and Nicotine Levels in Saliva and in the Ultrafiltrate of a Nonsmoker

After smoking two cigarettes, the nicotine and cotinine concentrations in the ultrafiltrate of the nonsmoker increased within a few minutes. While the nicotine concentration rose abruptly within $15 \mathrm{~min}$ to values exceeding $300 \mathrm{ng} / \mathrm{ml}$, cotinine increased steadily to reach about $20 \mathrm{ng} / \mathrm{ml} 2 \mathrm{hr}$ after smoking (Fig. 2). Nicotine concentrations, artificially elevated until $2 \mathrm{hr}$ fell rapidly to reach baseline levels after about $6 \mathrm{hr}$. Cotinine concentrations, however, were still significantly higher after $25 \mathrm{hr}$ than presmoking levels.

The patterns of nicotine and cotinine concentration were similar in whole saliva and in the ultrafiltrate (Fig. 3). It is almost certain that the immediate rise of nicotine after smoking to $>300 \mathrm{ng} / \mathrm{ml}$ does not reflect concentrations in the blood circulation but originates from the sequestered substance in the buccal cavity.

Cotinine and Nicotine Levels before, during, and after Temporary Abstinence in a Regular Smoker

Cotinine concentrations of a subject smoking an average of 15 cigarettes per day were between 120 and $210 \mathrm{ng} / \mathrm{ml}$ in the ultrafiltrate of saliva (Fig. 4). After cessation of smoking, the concentration was still significantly higher than baseline levels at 5 days $(3.6 \mathrm{ng} / \mathrm{ml})$. Immediately after resuming smoking, cotinine concentrations rose and remained between 30 and $60 \mathrm{ng} / \mathrm{ml}$. During this period, the person smoked only about 5 cigarettes per day.

At the time of abstinence, elevated nicotine levels were occasionally measured. Since failure to detect cotinine tends to confirm the subject's self-report of abstinence, these small elevations probably resulted from passive smoking. After resuming smoking (average of 5 cigarettes per day), little difference in the concentration of nicotine to the period of abstinence can be observed.

\section{DISCUSSION}

Saliva can be obtained noninvasively and is therefore superior to blood as a biological medium for many applications. Whether saliva is preferable to urine may depend on the circumstances: the controversies over invasion of privacy

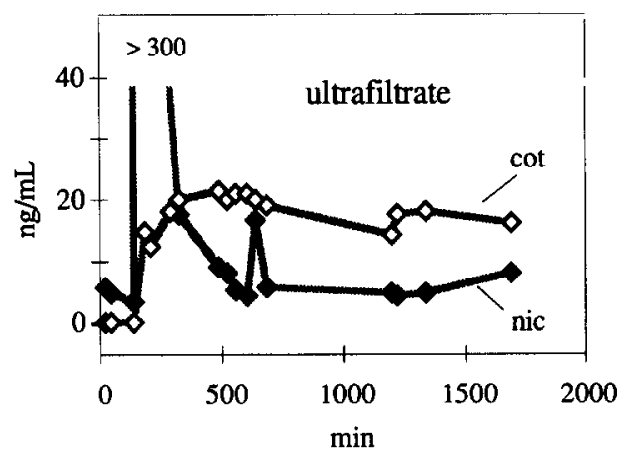

FIG. 2. Concentration of nicotine (nic) and cotinine (cot) over time in the ultrafiltrate of saliva of a nonsmoker after smoking two cigarettes (at $170 \mathrm{~min})$. After more than 1 day $(1,700 \mathrm{~min})$, the elevation of cotinine was still significant. 


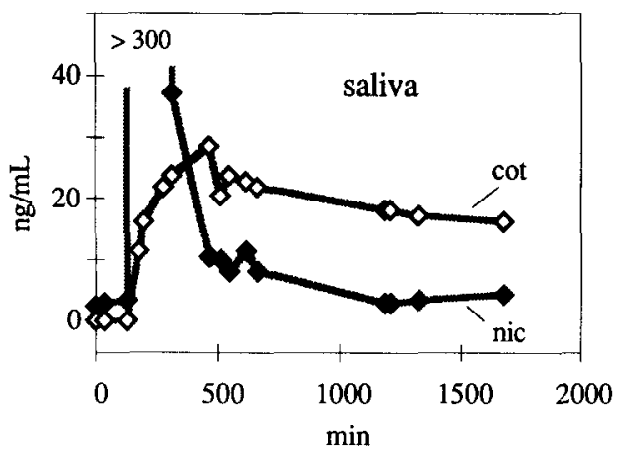

FIG. 3. Concentration of nicotine (nic) and cotinine (cot) over time in the whole saliva of a nonsmoker. The samples were simultaneously collected with those as shown in Fig. 2.

regarding the collection of urine samples for the assessment of drug abuse are well known; on the other hand, a patient visiting the physician might prefer to provide a urine sample than to expectorate. In appreciation of these limitations, methods have been developed to collect saliva by means of cotton plugs (dental roll) that are subsequently centrifuged to extract liquid. High nonspecific binding of analytes can be expected on the large surface area, however, and caution has been recommended in using such methods $(24,25)$. The device used in this study has a much smaller surface area. It also prepurifies saliva in situ by excluding particulate matter and molecules $>12,000 \mathrm{Da}$, thus yielding a clear liquid within a few minutes that does not need to be centrifuged.

The volume of ultrafiltrate that was collected in 8 min was sufficient for the quantitative analysis by HPLC. The determination of cotinine by immunoassay requires even less volume, i.e., about $25 \mu \mathrm{l}$. If, for other applications, more sample volume should be required, two of the devices can be used either simultaneously or consecutively.

A disadvantage of using the ultrafiltrate seems to be the monitoring of the density for calculating the concentration of analytes. Variability of density is quite small, however, so that in instances in which determining the density poses dif-

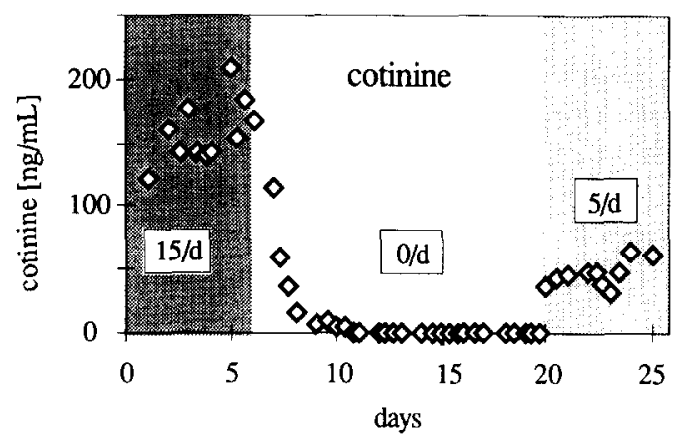

FIG. 4. Concentration of cotinine over time in the ultrafiltrate of saliva of an individual who smoked an average of 15 cigarettes per day (15/d), stopped smoking (0/d), and resumed smoking (average of 5 cigarettes per day, $5 / \mathrm{d}$ ). 


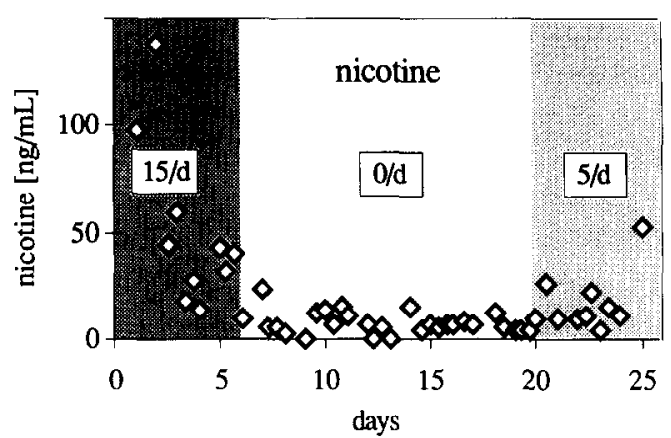

FIG. 5. Concentration of nicotine over time in the ultrafiltrate of saliva in the same samples as shown in Fig. 4. Nicotine is a less reliable indicator of smoking than the metabolite cotinine.

ficulties, the use of a constant produces satisfactory results (e.g., an average density of $1.12 \mathrm{~g} / \mathrm{ml}$ in this study).

In these and similar experiments (20-22), we have not experienced breakage of the semipermeable membrane, although subjects were instructed not to chew on the device. If more protection should be required for other applications (e.g., for the involuntary collection of ultrafiltrate) the osmotic device can be enclosed in a perforated silicon sleeve.

We have demonstrated that the device can be used for the quantitative determination of cotinine in saliva. The validity of saliva as a medium for the measurement of cotinine has been previously established in studies comparing concentrations and correlations among saliva, plasma, and urine (10-13). Our investigations have shown an excellent correlation between cotinine concentrations in whole saliva and the ultrafiltrate, and between plasma and the ultrafiltrate (Fig. 1). The concentrations of nicotine correlate less in the three media.

Nicotine is metabolized to more than 20 different derivatives (26). The major metabolite is cotinine, which is specific to tobacco smoking, tobacco chewing, and the use of nicotine gum. With an average half-life of about $19 \mathrm{hr}$ in smokers (27), this derivative is an excellent marker for nicotine exposure. It has been widely used as a biological marker of smoking in epidemiological studies $(4,6-8$, $10,28,29)$. The concentration of cotinine in body fluids can give an estimate of nicotine exposure for up to 2 or 3 days after cigarette smoking. In fact, we demonstrated elevated cotinine levels in the ultrafiltrate and in whole saliva for more than $24 \mathrm{hr}$ after smoking of two cigarettes by a nonsmoker (Figs. 2 and 3). The patterns for concentration over time were similar in the two fluids.

Cotinine concentrations in the ultrafiltrate are clearly related to the number of cigarettes smoked per day. While the mean concentration of cotinine was 157 $\mathrm{ng} / \mathrm{ml}(\mathrm{SD} \pm 25.7 \mathrm{ng} / \mathrm{ml})$ when the subject reported smoking a mean of 15 cigarettes per day, the concentration was $47 \mathrm{ng} / \mathrm{ml}(\mathrm{SD} \pm 10.5)$ during the 10 days that the subject reported smoking a mean of 5 cigarettes per day (Fig. 4). Such a doseresponse relationship, however, may extend only to samples from the same individual, because metabolism of nicotine to cotinine can vary substantially between individuals, depending on age, sex, and smoker vs. non-smoker $(11,30)$. 
After cessation of smoking by a habitual smoker, elevated cotinine levels could be detected for up to 5 days $(3 \mathrm{ng} / \mathrm{ml}$; Fig. 4). It is very difficult to compare these results with similar studies, since large variations in cotinine levels (31) and in rates of metabolizing nicotine (32) are possible. Moreover, unless subjects are closely supervised in cessation studies, it is not possible to confirm abstinence. Elevated cotinine concentrations in saliva $(>10 \mathrm{ng} / \mathrm{ml}$ ) between 3 and 7 days after subjects stopped smoking (31), concentrations between 1.6 and $52 \mathrm{ng} / \mathrm{ml}$ after 2 days (32), and a fall of cotinine in "moderate smokers" (not specified) from 615 to $314 \mathrm{ng} / \mathrm{ml} 7$ days after cessation of smoking (16) have been reported. These concentrations can be compared to levels of less than $5 \mathrm{ng} / \mathrm{ml}$ in passive smokers, although in heavy passive smokers levels $>10 \mathrm{ng} / \mathrm{ml}$ have been reported (33).

These experiments presented here were designed to investigate the utility of an ultrafiltrate of saliva for the measurement of cotinine in a limited number of human subjects. It is reasonable to expect that the cost of the device for the collection of ultrafiltrate, if manufactured on a large scale, should justify its applicability in public health studies. To extend the results, future independent investigations should address the issues of generalizability and cost-effectiveness in field trials, epidemiological studies, and passive exposure to smoke.

\section{CONCLUSIONS}

The use of the osmotic device facilitated sample collection and processing substantially. When the resulting ultrafiltrate was assayed for cotinine, concentrations comparable to those in whole saliva and plasma were observed. The device thus appears to have many advantages to other available methodologies for the determination of smoking status in settings where the noninvasive collection of a sample is desired. We are now testing modifications of the device where the collector is placed inside a perforated pacifier for studies with children. Another version with the collector enveloped by a perforated silicon rubber sleeve for protection and with a tether attached that hangs out of the mouth during use (e.g., for use by law enforcement agencies) is being developed.

\section{ACKNOWLEDGMENTS}

We thank Dr. M. Hariharan, University of Michigan Medical School, for performing the nicotine and cotinine assays and Drs. Paul A. Craig and Richard H. Smith for helpful discussions. The authors also thank Susan M. Basson and Karen A. Flessland for their assistance in carrying out this study. The research was funded in part by National Cancer Institute Grant CA 42730 to the second author and in part by the National Institute on Drug Abuse (R43 DA05982) to the first author.

\section{REFERENCES}

1. Pechacek TF, Murray DM, Luepker RV, Mittelmark MB, Johnson CA, Shutz JM. Measurement of adolescent smoking behavior: Rationale and methods. J Behav Med 1984; 7:123-140.

2. Biglan A, Gallison C, Ary D, Thompson R. Expired air carbon monoxide and salivary thiocyanate: Relationship to self-reports of marijuana and cigarette smoking. Addict Behav 1985; 10:137-144.

3. McNeill AD, West RJ, Jarvis MJ, Russell MA. Do other children take in more smoke from their cigarettes? Evidence from carbon monoxide levels. J Behav Med 1986; 9:559-565. 
4. Jarvis MJ, Tunstall-Pedoe H, Feyerabend C, Vesey C, Saloojee Y. Biochemical markers of smoke absorption and self reported exposure to passive smoking. $J$ Epidemiol Community Health $1984 ; 38: 335-339$.

5. Wald NJ, Boreham J, Bailey A, Ritchie C, Haddow JE, Knight G. Urinary cotinine as a marker of breathing other people's tobacco smoke. Lancet 1984; 1:230-231.

6. McNeill AD, Jarvis MJ, West R, Russell MA, Bryant A. Saliva cotinine as an indicator of cigarette smoking in adolescents. Br J Addict 1987; 82:1,355-1,360.

7. McNeill AD, Jarvis MJ, Stapleton JA, West RJ, Bryant A. Nicotine intake in young smokers: Longitudinal study of saliva cotinine concentrations. Am J Public Health 1989; 79:172-175.

8. Jarvis MJ, Russell MA, Feyerabend C, Eiser JR, Morgan M, Gammage P, et al. Passive exposure to tobacco smoke: Saliva cotinine concentrations in a representative population sample of non-smoking schoolchildren. Br Med J 1985; 291:927-929.

9. Coultas DB, Howard CA, Peake GT, Skipper BJ, Samet JM. Salivary cotinine levels and involuntary tobacco smoke exposure in children and adults in New Mexico. Am Rev Respir Dis 1987; 136:305-309.

10. Jarvis MJ, Russell MA, Benowitz NL, Feyerabend C. Elimination of cotinine from body fluids: Implications for noninvasive measurement of tobacco smoke exposure. Am J Public Health 1988; 78:696-698.

11. Curvall M, Enzell CR. Monitoring absorption by means of determination of nicotine and cotinine. Arch Toxicol Suppl 1986; 9:88-102.

12. Langone JJ, Van Vunakis H. Radioimmunoassay of nicotine, cotinine, and $\gamma$-(3-pyridyl)- $\gamma$-oxo$N$-methylbutyramide. In: Langone JJ, Van Vunakis H, Eds. Methods in Enzymology, Vol. 84, Immunochemical Techniques, Part D. New York: Academic Press, 1982:628-640.

13. Jarvis MJ, Russell MA, Feyerabend C. Absorption of nicotine and carbon monoxide from passive smoke under natural conditions of exposure. Thorax 1983; 38:829-833.

14. Di Giusto E, Eckhard I. Some properties of saliva cotinine measurements in indicating exposure to tobacco smoking. Am J Public Health 1986; 76:1,245-1,246.

15. Van Vunakis H, Tashkin AP, Rigas B, Simmons M, Gjika HB, Clark VA. Relative sensitivity and specificity of salivary and serum cotinine in identifying tobacco-smoking status of self-reported nonsmokers and smokers of tobacco and/or marijuana. Arch Environ Health 1989; 44:53-58.

16. Sepkovic DW, Haley NJ. Biomedical applications of cotinine quantitation in smoking related research. Am J Public Health 1985; 75:663-665.

17. United States National Research Council (USNRC). Environmental Tobacco Smoke: Measuring Exposures and Assessing Health Effects. Washington, DC: Nat. Acad. Sci.-Nat. Res. Council, 1986:145.

18. United States Public Health Service (USPHS). A Report of the Surgeon General: Deposition and Absorption of Tobacco Smoke Constituents: The Health Consequences of Involuntary Smoking. Atlanta, GA: U.S. Department of Health and Human Services, Public Health Service, Centers for Disease Control, 1986: $209 \mathrm{ff}$.

19. Knott C, Reynolds F. The place of saliva in antiepileptic drug monitoring. Ther Drug Monit 1984; 6:35-41.

20. Schramm W, Paek S-H, Kuo H-H, Yang T. Ultrafiltrate of saliva collected in situ for the measurement of testosterone. Anal Chim Acta 1991; 248:517-528.

21. Schramm W, Annesley TM, Siegel GJ, Sackellares JC, Smith RH. Measurement of phenytoin and carbamazepine in an ultrafiltrate of saliva. Ther Drug Monit 1991; 13, in press.

22. Schramm W, Smith RH, Craig PA, Paek S-H, Kuo H-H. Determination of free progesterone in an ultrafiltrate of saliva collected in situ. Clin Chem 1990; 36:1,488-1,493.

23. Hariharan M, Van Noord T, Greden JF. A HPLC method for the routine simultaneous determination of nicotine and cotinine in plasma. Clin Chem 1988; 34:724-729.

24. Walker RF, Robinson JA, Roberts S, Ford PD, Riad-Fahmy D. Experience with the Sarstedt Salivette in salivary steroid determinations. Ann Clin Biochem 1990; 27:503-505.

25. Arglebe C. Experience with the Salivatte and some findings concerning its applicability for the determination of salivary components. J Clin Chem Clin Biochem 1989; 27:247-248.

26. Pilotti A. Biosynthesis and mammalian metabolism of nicotine. Acta Physiol Scand Suppl 1980; 479:13-17. 
27. Benowitz NL. The use of biological fluid samples in assessing tobacco smoke exposure. In: Grabowski J, Bell CS, Eds. Measurement in the Analysis and Treatment of Smoking Behavior. NIDA Research Monograph 48. Rockville, MD; U.S. Department of Health and Human Services, 1983:6-26.

28. Jarvis MJ. Uptake of environmental tobacco smoke. In: O'Neill IK, Brunneman KD, Dodet B, Hoffman D, Eds. Environmental Carcinogens-Methods of Analysis and Exposure Measurement, Passive Smoking. Scientific Publication No. 81. Lyon, France: International Agency for Research on Cancer, 1987:43-58.

29. Jarvis MJ, Tunstall-Pedoe H, Feyerabend C, Vesey C, Saloojee Y. Comparison of tests used to distinguish smokers from nonsmokers. Am J Public Health 1987; 77:1,435-1,438.

30. Sepkovic DW, Haley NJ, Hoffman D. Elimination from the body of tobacco products by smokers and passive smokers [letter]. $J$ Am Med Assoc 1986; 256:863.

31. Abrams DB, Follick MJ, Biener L, Carey KB, Hitti J. Saliva cotinine as a measure of smoking status in field settings. Am J Public Health 1987; 77:846-848.

32. Machacek DA, Jiang NS. Quantification of cotinine in plasma and saliva by liquid chromatography. Clin Chem 1986; 32:979-982.

33. Etzel RA. A review of the use of saliva cotinine as a marker of tobacco smoke exposure. Prev Med 1990; 19:190-197.

Received April 1, 1991

Revised July 17, 1991

Accepted July 17, 1991 